\title{
Assessment of energy efficiency in street lighting design
}

\author{
J. Silva ${ }^{1}$, J. F. G. Mendes ${ }^{2} \&$ L. T. Silva ${ }^{2}$ \\ ${ }^{I}$ Department of Civil Engineering, Polytechnic of Viana do Castelo, \\ Portugal \\ ${ }^{2}$ Department of Civil Engineering, University of Minho, Portugal
}

\begin{abstract}
Street lighting design aims to ensure adequate night visibility conditions for both vehicular and pedestrian traffic as well as to improve security conditions for persons, goods and property in the neighbourhood. In addition to this, and in order to meet concerns about environmental protection and sustainable development, the design of street lighting should take into account the optimization of its energy efficiency, as excessive energy usage is associated with an increase in polluting emissions, namely $\mathrm{CO} 2$. Considering that street lighting generally presents a significant consumption of electricity that is often possible to reduce, the use of good design practices which will maximize the efficiency of lighting equipments and accessories as well as minimize the upward light emissions and adjust the intensity of lighting according to outdoor needs is crucial. The main goal of this work is to present a new simple tool which can assess street lighting performance in the context of energy efficiency. Three indicators were developed: one to evaluate lighting performance and two others to evaluate energy performance. These indicators were quantified and combined according to weighting and aggregation procedures, resulting in a synthetic score for the street lighting design. The assessment tool was applied to a business park located in Viana do Castelo, in Portugal, and the results are discussed.
\end{abstract}

Keywords: street lighting, street lighting design, street lighting assessment, energy efficiency. 


\section{Introduction}

A tool for assessing the quality of business parks design, called AQPZE, was developed in Portugal by a team from the Polytechnic of Viana do Castelo and the University of Minho [1]. The assessment focuses on twelve project components which basically refer to the main public utilities, facilities, amenities and other issues that should be considered in business parks design, as follows: i) street network; ii) water supply; iii) sanitary sewerage; iv) storm sewerage; v) electricity supply; vi) gas supply; vii) telecommunications; viii) street lighting; ix) solid waste disposal; x) facilities and amenities; xi) zoning and lot layout; xii) landscape.

The tool uses a multicriteria approach based on a hierarchical tree structure, where a set of lower level criteria contributes to the assessment of the next higher-level criteria or dimension. The assessment of each bottom lower level criterion is achieved by using an indicator or a set of dependent indicators that reflect the performance of the adopted design solutions in that domain. Altogether, the model incorporates 122 indicators, 50 criteria divided into two hierarchical levels and 12 dimensions, corresponding to the 12 identified project components. The tool, in addition to the settlement of a global index, which reflects the quality of business park design as a whole, allows the acquisition of partial scores corresponding to the performance of each dimension or criterion. Thus, it may cumulatively assess the quality of the design within its specialised disciplines.

One of the engineering disciplines that is assessed is the street lighting. Similarly to other dimensions, together with the analysis of the functional performance of this engineering project, it is taken into consideration the evaluation of its sustainability, measured in terms of energy efficiency.

\section{The street lighting}

The street lighting primarily seeks to ensure adequate visibility conditions suitable for both vehicles and pedestrians during the hours of darkness. This contributes to promote the safety and smooth flow of road traffic, as well as to improve the public safety and order, particularly of pedestrians, facilities and goods of the surrounding public sites. In addition to this, and in order to meet concerns about environmental protection and sustainable development, the design of street lighting should take into account the optimization of its energy efficiency, as excessive energy usage is associated with an increase in polluting emissions, namely $\mathrm{CO} 2$. Considering that street lighting generally presents a significant consumption of electricity that is often possible to reduce, the use of good design practices which will maximize the efficiency of lighting equipment and accessories as well as minimize the upward light emissions and adjust the intensity of lighting according to outdoor needs is crucial [2].

These latest issues, in spite of being relatively recent concerns, have been lately seen in an objective way and led to regulations that express concerns both to ensure adequate lighting quality and also to achieve good energy efficiency. 


\section{Formulation}

Each dimension is assessed by using one or more associated dependent criteria. On the other hand, each criterion is assessed by using one or more indicators, which can be measured and evaluated. These indicators measure the performance of the design solutions. This measurement is carried out by using a transformation function which gives a score, with a value ranging on a scale of 0 to 1. Subsequently, the score of each criterion is achieved through the combination of the scores from dependent indicator. Similarly, combining the dependent criteria, it will be obtained the score of the dimension.

In all cases, to combine indicators and criteria, procedures for weighting and aggregation are developed. The weights associated with each indicator and each criterion are then set. The aggregation is now set based on the method of Weighted Linear Combination (WLC) [3], according to Equation (1):

$$
S=\sum_{n} w_{i} x_{i}
$$

where:

$S$ is the final score,

$w_{i}$ is the weight of the criterion or indicator $i$, as follows:

$$
\sum_{n} w_{i}=1
$$

$x_{i}$ is the score of the criterion or indicator $i$ standardized in a $0-1$ range;

$n$ is the number of dependent criterion or indicators of a same hierarchical level.

The assessment of street lighting results from the weighted linear combination of two normalised criteria: lighting performance and energy performance. The criterion lighting performance is evaluated by using a single indicator called luminaire coverage and average illumination level. The criterion energy performance is then assessed by using two indicators: the luminaire coverage and efficiency and the lighting control devices (Fig. 1).

\subsection{Lighting performance}

The street lighting comprises a set of luminaires and its lamps which are usually fixed on lampposts and lined up in a uniform layout along the area to be lit. The purpose of the luminaire is to direct the best way the luminous flux towards the surface is going to illuminate and thus, controlling and improving the performance of light sources. A luminaire consists of housing, an electrical unit and an optical system, which has a reflector and an optical enclosure.

The street lighting performance is only evaluated on the basis of the target light levels, according to the class of area to be illuminated. Other parameters such as illuminance uniformity, shadow control, glare or colour rendering are not taken into consideration for this purpose. So, this criterion is assessed by using a single indicator called luminaire coverage and average illumination level, that shows the night lighting levels of the public spaces. 


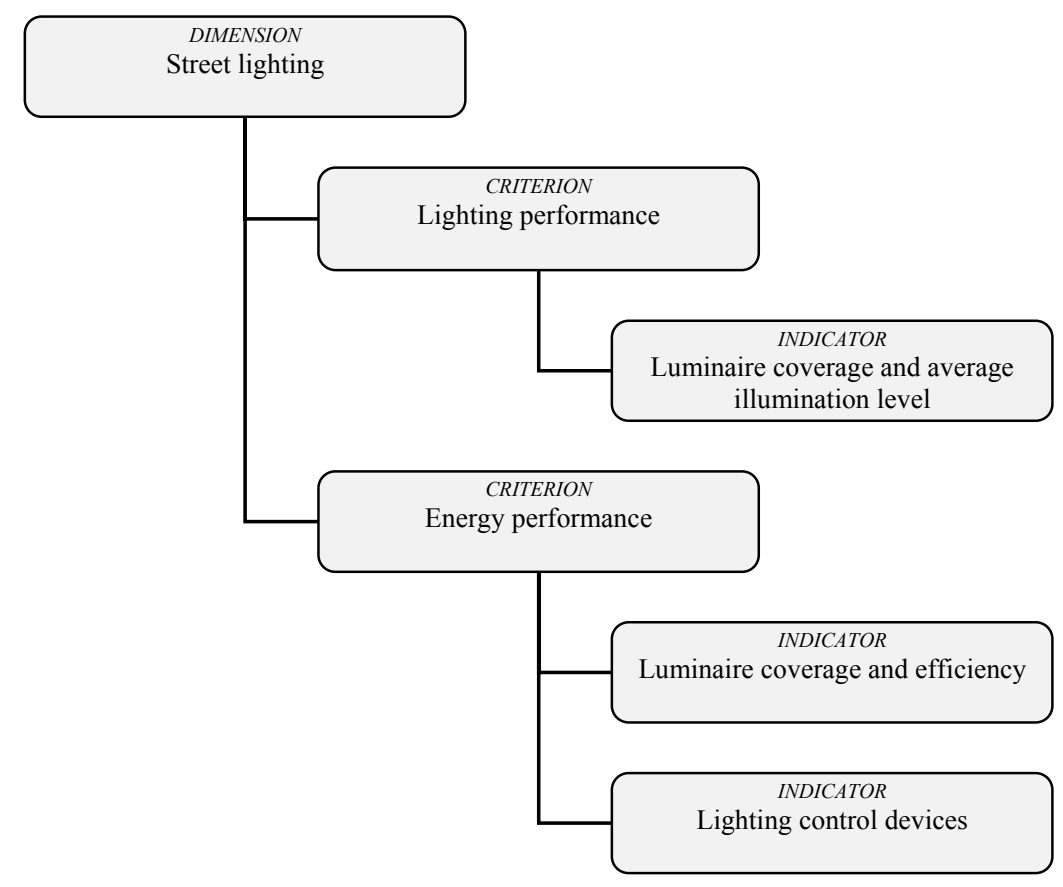

Figure 1: $\quad$ Street lighting assessment criteria and indicators.

The score of this indicator is calculated according to the following steps:

i) The areas that should have street lighting are divided into the following classes:

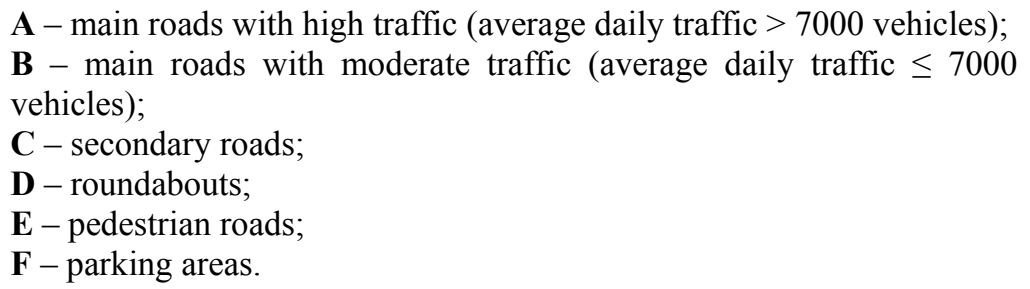

ii) For each class of area it is calculated the Project Average Illumination Level $E m_{p}$, through the lumen method [4-6], using Equation (2):

$$
E m_{p}=\frac{\phi_{L} \times f_{m} \times f_{u}}{d \times A}
$$

where:

$E m_{p}$ is the project average illumination level [lux];

$\varnothing_{L}$ is the luminous flux of the lamp(s) [lm]; 
$f_{m}$ is the maintenance or deprecation factor;

$f_{u}$ is the utilization factor;

$d$ is the luminaires spacing [m];

$A$ is the road width to be lit [m].

iii) For each class of area it is set the Target Average Illumination Level Em $m_{r}$, according to Table 1 (adapted from [7-9]):

Table 1: $\quad$ Target average illumination level.

\begin{tabular}{|c|c|c|c|c|c|c|}
\hline Class of area & A & B & C & D & E & F \\
\hline $\begin{array}{c}\text { Target Average Illumination } \\
\text { Level Em } m_{r}[\text { lux }]\end{array}$ & 15 & 10 & 7.5 & 20 & 7.5 & 10 \\
\hline
\end{tabular}

iv) For each class of area, it is calculated the score Average Illumination Level Sil, taking into account the ratio between the Project Average Illumination Level $\mathrm{Em}_{p}$ and the Target Average Illumination Level Em $r$, using the transformation function (Equation (3)):

$$
\begin{array}{ll}
\text { Sil }=\left(E_{\mathrm{p}} / \mathrm{Em}_{\mathrm{r}}\right) & \text { if } 0 \leq\left(\mathrm{Em}_{\mathrm{p}} / \mathrm{Em}_{\mathrm{r}}\right) \leq 1 \\
\text { Sil }=-1 / 2\left(\mathrm{Em}_{\mathrm{p}} / \mathrm{Em}_{\mathrm{r}}\right)+3 / 2 & \text { if } 1<\left(\mathrm{Em}_{\mathrm{p}} / \mathrm{Em}_{\mathrm{r}}\right) \leq 3 \\
\text { Sil }=0 & \text { if }\left(\mathrm{Em}_{\mathrm{p}} / \mathrm{Em}_{\mathrm{r}}\right)>3
\end{array}
$$

v) The final score of the indicator Luminaire Coverage and Average Illumination Level Scil, is calculated for all classes of area through Equation (4):

$$
\text { Scil }=\sum_{n} \text { Extension }_{i} \times \text { Coverage }_{i} \times \text { Sil }_{i}
$$

where:

Extension $_{i}$ is the ratio between the surface of the class $i$ area and the total surface for all classes of area;

Coverage $_{i}$ is the ratio between the surface of the class $i$ area actually covered by street lighting and the total surface of that class;

$\mathrm{Sil}_{i}$ is the score Average Illumination Level of the class $i$ area.

\subsection{Energy performance}

The energy efficiency can be defined as the ratio between the useful energy output and the consumed energy. In the case of the street lighting, the energy efficiency can be expressed as the ratio between the average illumination level and the consumed electrical power. Regarding the street lighting energy efficiency, there are two factors of major importance: the efficacy of the lamps and the luminaire efficiency.

The efficacy of a lamp, expressed in $1 \mathrm{~m} / \mathrm{W}$, represents the ratio between the luminous flux emitted by the lamp and its consumed power. This efficacy varies largely depending on the type of lamp used (mercury vapour, metal halide, low- 
pressure sodium vapour, high pressure sodium vapour or others), and its power. The efficiency of a luminaire reflects the ratio between the luminous flux it emits, and that produced by the lamp or lamps inside it. The efficiency varies according to the type of luminaire and its photometry, specially its optical system [10].

When assessing the energy efficiency of the street lighting, it should be taken into account another factor that is related to the way the luminaire is switched on or off and the way the luminous flux is adjusted. In order to optimise energy consumption, it should be avoided a too early switch on and/or a too late switch off. It is also advisable to reduce the power consumption and the associated luminous flux at dusk. In the case of the working period of the lighting system, this is achieved through switches operated by a timer or a light sensor. In the case of the adjustment of the luminous flux, this is achieved through dimmers capable of reducing the .power consumption [11].

Thus, the criterion energy performance is assessed by using two indicators, one being luminaire coverage and efficiency and the other lighting control devices.

\subsubsection{Luminaire coverage and efficiency}

This indicator shows the energy efficiency of street lighting in a night environment and evaluates the efficiency of the system regarding its coverage. The score of this indicator is calculated according to the following steps:

i) The areas that should have street lighting are, as mentioned in the previous indicator, divided into classes A, B, C, D, E and F.

ii) For each class of area, as it happens with the previous indicator, it is calculated the Project Average Illumination Level Em, through the lumen method, using Equation (2).

iii) For each class of area it is calculated, the Project Efficacy $R_{p}$ using Equation (5):

$$
R_{p}=\frac{E_{m p}}{P}
$$

where:

$R_{p}$ is the project efficacy $[\mathrm{lm} / \mathrm{W}]$;

$E_{m p}$ is the project average illumination level [lux];

$P$ is the installed power of the lamps per unit area of the illuminated surface $[\mathrm{W} / \mathrm{m} 2]$.

iv) It is set a Target Efficacy $R_{r}$ of $19 \mathrm{~lm} / \mathrm{W}$ for all classes of area.

v) For each class of area, it is calculated the score Efficiency $S r$, taking into account the ratio between the Project Efficacy $R_{p}$ and the Target Efficacy $R_{r}$ through the transformation function (Equation (6)):

$$
\begin{array}{ll}
S r=\left(\mathrm{R}_{\mathrm{p}} / \mathrm{R}_{\mathrm{r}}\right) & \text { if } 0 \leq \mathrm{R}_{\mathrm{p}} / \mathrm{R}_{\mathrm{r}} \leq 1 \\
S r=1 & \text { if } \mathrm{R}_{\mathrm{p}} / \mathrm{R}_{\mathrm{r}}>1
\end{array}
$$


vi) The final score of the indicator Luminaire Coverage and Efficiency Scr, is calculated for all classes of area through Equation (7):

$$
\text { Scr }=\sum_{n} \text { Extension }_{i} \times \text { Coverage }_{i} \times \text { Sr }_{i}
$$

where:

Extension $_{i}$ is the ratio between the surface of the class $i$ area and the total surface for all classes of area;

Coverage $_{i}$ is the ratio between the surface of the class $i$ area actually covered by street lighting and the total surface of that class;

$\mathrm{Sr}_{i}$ is the score Efficiency of the class $i$ area.

\subsubsection{Lighting control devices}

This is an indicator of the energy efficiency of street lighting at dusk and also the way the system is capable of switching on or off. Thus, the assessment is based on two second level indicators, which take into account the existence of dimmers capable of reducing the luminous flux and the power consumption of the lighting and automatic time switch control devices capable of adjusting the working periods.

The score of the indicator Lighting Control Devices $S_{d f}$, is calculated for all classes of area by using two $2^{\text {nd }}$ level indicators through Equation (8):

$$
S_{d f}=\frac{S_{d r f}+S_{d r c}}{2}
$$

where:

$S_{d r f}$ is the score of $2^{\text {nd }}$ level indicator Dimmers (Table 2);

$S_{d r c}$ is the score of $2^{\text {nd }}$ level indicator Automatic Time Switch Control Devices (Table 3).

Table 2: $\quad$ Dimmers.

\begin{tabular}{|c|c|}
\hline Score & Device type \\
\hline 1.00 & $\begin{array}{c}\text { Amplitude control, supply voltage reduction, } \\
\text { phase control or other power reduction methods }\end{array}$ \\
\hline 0.00 & $\begin{array}{c}\text { There are no plans available to reduce the } \\
\text { luminous flux }\end{array}$ \\
\hline
\end{tabular}

Table 3: $\quad$ Automatic time switch control devices.

\begin{tabular}{|c|c|}
\hline Score & Device type \\
\hline 1.00 & Time switches or light sensor switches \\
\hline 0.00 & $\begin{array}{r}\text { There are no plans available to adjust the } \\
\text { working periods in an automatic way }\end{array}$ \\
\hline
\end{tabular}




\section{Case study: business park of Lanheses}

The assessment tool of street lighting energy efficiency was applied to Lanheses Business Park, which is located in Viana do Castelo, in the north of Portugal. This is a new generation business park, whose phase 1 covers a total area of $150.074 \mathrm{~m}^{2}$, including $56.805 \mathrm{~m}^{2}$ to build 33 lots for industry, storage and facilities (Fig. 2).

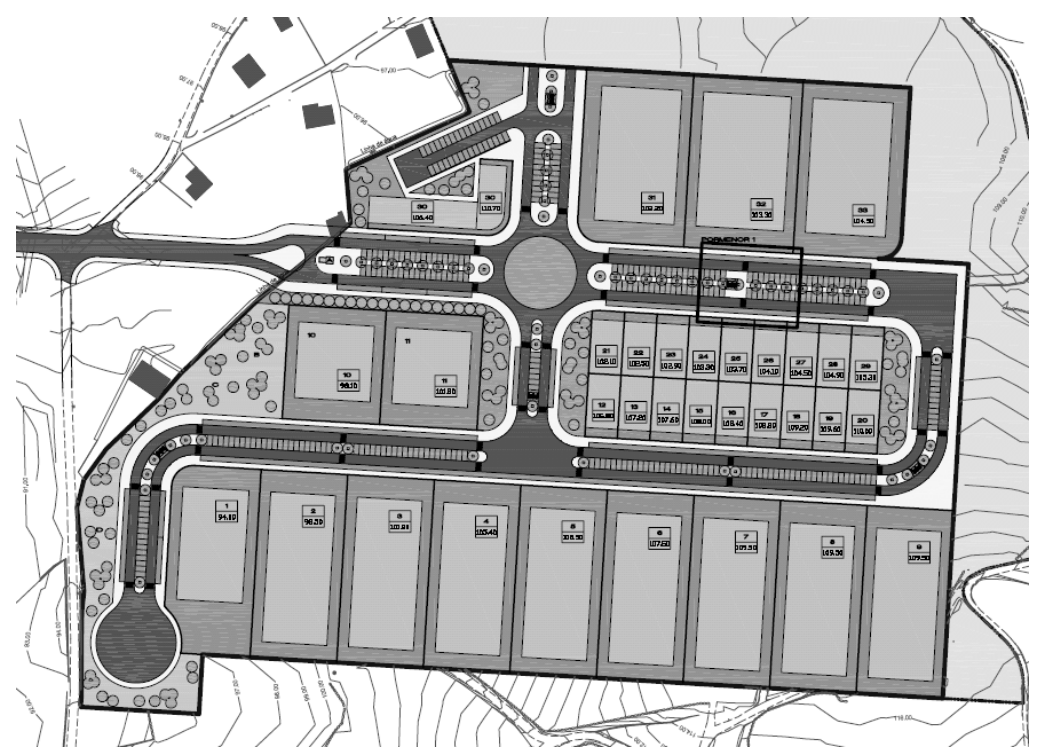

Figure 2: $\quad$ Plan of Lanheses business park.

The street lighting is located along the street network of the park. It consists of 10 meters high steel lampposts headed by one, two or three arms, all of them equipped with a luminaire that contains a high-pressure sodium vapour lamp (HPS) of $250 \mathrm{~W}$. The double-arm lampposts are the basic solution adopted and they are located along the street network. The triple-arm columns are located in the roundabouts and in the south $\mathrm{T}$-junction, while the one-arm columns are used in the car parking in the north, and in the roundabout in the southwest.

The evaluation for each of the three indicators can be observed in Table 4. For each indicator it is presented the score and relevant comments are made.

Table 5 shows the combination of all the indicators and criteria, which led to a final score of 0.61 for the dimension Street Lighting. For each indicator and each criterion it is indicated their weights. It is also calculated, according to Equation (1), the partial scores for each criterion, always with values ranging on a scale of 0 to 1 . 
Table 4: $\quad$ Street lighting indicators evaluation.

\begin{tabular}{|c|c|c|c|}
\hline Criterion & Indicator & Score & Comments \\
\hline $\begin{array}{l}\text { Lighting } \\
\text { performance }\end{array}$ & $\begin{array}{c}\text { Luminaire } \\
\text { coverage } \\
\text { and average } \\
\text { illumination } \\
\text { level }\end{array}$ & 0.30 & $\begin{array}{l}\text { Luminaire Schréder Onyx } 2 \text { with a } \\
\text { HPS lamp of } 250 \mathrm{~W} ; 10 \mathrm{~m} \text { high } \\
\text { lampposts with } 1.60 \mathrm{~m} \text { arm; class B } \\
\text { roads. } \\
\text { The score } S c i l \text { presents a low value } \\
\text { because the Project Average } \\
\text { Illumination Level Emp lies between } \\
18.0 \text { and } 27.6 \text { lux, which is clearly } \\
\text { higher than the target } E m r \text { value of } 10 \\
\text { lux; if HPS lamps of } 150 \mathrm{~W} \text { were } \\
\text { used, Scil would have presented a } \\
\text { value of } 0.84 \text {. }\end{array}$ \\
\hline \multirow[b]{2}{*}{$\begin{array}{c}\text { Energy } \\
\text { performance }\end{array}$} & $\begin{array}{l}\text { Luminaire } \\
\text { coverage } \\
\text { and } \\
\text { efficiency }\end{array}$ & 0.81 & $\begin{array}{l}\text { Luminaire Schréder Onyx } 2 \text { with a } \\
\text { HPS lamp of } 250 \mathrm{~W} ; 10 \mathrm{~m} \text { high } \\
\text { lampposts with } 1.60 \mathrm{~m} \text { arm. } \\
\text { Project Efficacy } R_{p} \text { lies between } 11.3 \\
\mathrm{~lm} / \mathrm{W} \text { and } 17.4 \mathrm{~lm} / \mathrm{W} \text {, and the Target } \\
\text { Efficacy } R_{r} \text { is } 19 \mathrm{~lm} / \mathrm{W} \text {. }\end{array}$ \\
\hline & $\begin{array}{l}\text { Lighting } \\
\text { control } \\
\text { devices }\end{array}$ & 1.00 & $\begin{array}{l}\text { There have been considered time } \\
\text { switches. } \\
\text { Dimmers to reduce the luminous flux } \\
\text { have not been considered in the design } \\
\text { because the electricity authority does } \\
\text { not approve such devices; so they have } \\
\text { not been considered in the evaluation } \\
\text { process. }\end{array}$ \\
\hline
\end{tabular}

Table 5: $\quad$ Combination of indicators and criteria.

\begin{tabular}{|c|c|c|c|c|c|c|c|}
\hline Dimension & Score & Criterion & Score & Weight & Indicator & Score & Weight \\
\hline & & $\begin{array}{c}\text { Lighting } \\
\text { perfor- } \\
\text { mance }\end{array}$ & 0.30 & 0.48 & $\begin{array}{c}\text { Luminaire } \\
\text { coverage } \\
\text { and average } \\
\text { illumination } \\
\text { level }\end{array}$ & 0.30 & 1.00 \\
\cline { 2 - 7 } $\begin{array}{c}\text { Street } \\
\text { Lighting }\end{array}$ & 0.61 & $\begin{array}{c}\text { Energy } \\
\text { perfor- } \\
\text { mance }\end{array}$ & 0.91 & 0.52 & $\begin{array}{c}\text { Luminaire } \\
\text { coverage } \\
\text { and } \\
\text { efficiency }\end{array}$ & 0.81 & 0.50 \\
\cline { 3 - 7 } & & $\begin{array}{c}\text { Lighting } \\
\text { control } \\
\text { devices }\end{array}$ & 1.00 & 0.50 \\
\hline
\end{tabular}




\section{Analysis and conclusions}

The dimension Street Lighting in Lanheses Business Park has a score of 0.61. This score is a combination of the partial scores obtained from the lighting performance and energy performance criteria, whose values are respectively 0.30 and 0.91 , so it can be said that the score reached for the first criterion was not suitable, nevertheless for the second was very satisfactory.

Indeed, the street lighting in Lanheses Business Park has as a strength its energy performance, understood as a measure of electrical power required to achieve the average illumination level. On the other hand, the street lighting has as a weakness its lighting performance. This weakness is due to the project average illumination level which shows values significantly higher than the target average illumination level, set at 10 lux. If it were used HPS lamps of $150 \mathrm{~W}$ instead of the $250 \mathrm{~W}$ ones, the score of the criterion lighting performance would have been presented a value of 0.84 and there would have been a consumption reduction in $40 \%$.

The tool assesses the energy performance of street lighting only taking into account the power consumed to achieve a well defined project average illumination level. So, it is not important whether the average illumination level is considered appropriate or not. The adequacy of the value of the project average illumination level is reflected only in the assessment of the lighting performance. Thus, the corresponding partial score is penalized if the average illumination level is insufficient or excessive. The overall assessment of the street lighting combines the two previous aspects, transforming them into a final index.

The optimization of energy efficiency should be a central concern in the street lighting design. This will enhance a major reduction in power consumption, which results in a significant environmental and economic benefit.

\section{References}

[1] Silva, J. Um Modelo de Avaliação da Qualidade de Projectos de Zonas Empresariais, PhD Thesis, Universidade do Minho, Braga, Portugal, 2008.

[2] Intelligent Energy Europe. Guide for Energy Efficient Street Lighting Installations, European Commission - Directorate General for Energy and Transport, Brussels, Belgium, 2007.

[3] Voogd, H. Multicriteria Evaluation for Urban and Regional Planning, Pion, London, UK, 1983.

[4] Schreuder, D. Outdoor Lighting: Physics, Vision and Perception, Springer Science + Business Media B.V., The Netherlands, 2008.

[5] DiLouie, C. The Lighting Management Handbook; The Fairmont Press, Lilburn, USA, 1994.

[6] Heredia, R. Arquitectura e Urbanismo Industrial - Diseño y construcción de plantas, edificios y polígonos industriales, Escuela Técnica Superior de Ingenieros Industriales de la Universidad Politécnica de Madrid, Madrid, Spain, 1981. 
[7] Commission Internationale de l'Eclairage (CIE). CIE 115 :1995 Recommendations for the Lighting of Roads for Motor and Pedestrian Traffic. CEI, Vienna, Austria, 1995.

[8] Comité Européen de Normalisation (CEN). EN 13201-2:2003 - Road Lighting: Performance Requirements. CEN, Brussels, Belgium, 2003.

[9] Comité Européen de Normalisation (CEN). CEN/TR 13201-1:2004 - Road Lighting: Selection of Lighting Classes. CEN, Brussels, Belgium, 2004.

[10] The Institution of Lighting Engineers. The Outdoor Lighting Guide; Taylor and Francis, Oxford, UK, 2005.

[11] Comité Español de Iluminación (CEI) y Instituto para la Diversificación y Ahorro de la Energía (IDAE). Propuesta de Modelo de Ordenanza Municipal de Alumbrado Exterior para la Protección del Medio Ambiente Mediante la Mejora de la Eficiencia Energética, IDAE, Madrid, Spain, 2002. 